\title{
VARIABILITY AND HERITAGE OF MORPHOPHYSOLOGICAL SYMPTOMS IN BIOLOGICAL PLANTS IN THE PROCESS OF SELECTION OF SUNBULL PLANTS
}

\author{
Aytjanov Baxytjan Uzaqbaevich ${ }^{1}$, Seytbaev Rauaj Sarsenbaevich ${ }^{2}$ \\ Aytjanov Uzaqbay Eshanovich ${ }^{3}$ \\ ${ }^{1}$ Doctor of Agricultural Sciences, Senior Researcher \\ ${ }^{2}$ Is a Basic Doctoral Student Karakalpak Institute of Agriculture and Agrotechnology, Nukus, \\ Uzbekistan \\ ${ }^{3}$ Doctor of Agricultural Sciences, Senior Researcher. Karakalpak Agricultural Research Institute, \\ Chimbay District, Uzbekistan
}

Article DOI: https://doi.org/10.36713/epra9169

DOI No: 10.36713/epra9169

\begin{abstract}
ANNOTATION
The total water content, dominance and flexibility coefficients in the leaves of $\mathrm{F}_{1}-\mathrm{F}_{2}-\mathrm{F}_{3}$ plants of hybrid combinations obtained from simple and complex hybridization to create a water-resistant selection material of sunflower from oilseeds were studied. This study showed that this trait is inherited differently in simple and complex $\mathrm{F}_{1}, \mathrm{~F}_{2}$ and $\mathrm{F}_{3}$ hybrids under different water regime conditions, with $\mathrm{F}_{2}$ hybrid combinations varying depending on the dominance coefficients and water supply conditions in hp as well as the composition of the parent forms of hybrids. The plants showed that the total amount of water in the leaves depends not only on the conditions of water supply but also on the genotypic composition

KEYWORDS: Sunflower, morphophysiological, heredity, hybrid, drought tolerance, yield, seed core, ripening, cohesion, variability, hybridological analysis.
\end{abstract}

\section{INTRODUCTION}

The role of oilseeds in the national economy is very significant. The oils extracted from them are the most important food product necessary for the daily life of our people. In addition, these oils play an important role in maintaining human health. In particular, the introduction of new varieties of accelerated type in production, increasing the yield of oilseeds, is one of the important resources for improving product quality. The success of the creation of such varieties depends largely on the source material. High yield success depends in many ways on how the raw materials are used. Selection of agricultural crops, including sunflower, uses simple and complex methods of achieving wide variability in valuable traits for the farm and new forms. Regardless of how the hybridization process is carried out, new plastic genotypes will emerge that can adapt and change to new living conditions as a result of genetic modification. Hybridization and selection is one of the main artificial methods of creating a new varieties, and its success will largely depend on the genotype of the selected mixing methods and starting materials. Due to limited water resources in Uzbekistan and the shortage of water in the region in recent years, the creation of drought-resistant varieties of sunflower is one of the main directions of genetics and selection of sunflower
According
to
D.T.Abdukarimov, T.E.Ostanakulov and M.K. Lukov [1], the yield of sunflower depends on the productivity of individual baskets and the number of plants per hectare. The productivity of a separate basket is determined by the number of seeds (pistachios) in it and the mass and weight of each seed. Here the amount of output of the seed core is of great importance. This figure depends on the output of the seed coat from the total mass. A $10 \%$ increase in the seed kernel (core) - leads to an increase in the amount of fat by 6-7\%.

According to M.Amanov, A.Rustamov [2], in the flowering phase of sunflower, after the fertilization process, a number of physiological and 


\section{EPRA International Journal of Research and Development (IJRD)

biochemical processes take place until the seed is fully mature. The period of complete formation of the seed consists of two stages, the first of which is the period of seed growth lasting 14-16 days. During this period, the nucleus of the seed is formed. Then in the second stage the accumulation of carbohydrates, proteins and fats of the main organic compounds from the seeds takes place in 20-25 days. The physiological maturation of the seed is characterized by the accumulation of dry matter in it and a decrease in moisture to $35 \%$.

According to R.Yu. Aliqulov, Sh.M. Khaldarov [3], one of the most important indicators of plant water balance is the total amount of water in the leaves.

Drought tolerance of varieties is the ability to withstand a lack of moisture in the soil, without drastically reducing their productivity and crop quality. At the same time, it is currently theoretically and practically important to study the specific genotypic susceptibility of new varieties of sunflower to different water regimes, including water scarcity conditions, and to increase the resilience potential of newly created varieties in their adaptive selection.

Taking into account the above, we study the basic physiological parameters to withstand water shortages in the natural soil-climatic conditions of Karakalpakstan through simple and complex hybridization methods in different irrigation schemes. we aimed to recommend their work.

\section{RESEARCH METHODS}

The research was conducted in the laboratory "Breeding and seed production of oilseeds" in the experimental farm of the Karakalpak Agricultural Research Institute.

The experiments began in 2019 and compared the variability, heredity, and scale of variability of some valuable farm traits in the generation of biological seedlings of simple and complex hybrids in the context of alternative water supply and water scarcity with hybridological analysis of parental forms. 50 plants from each of the varieties $\mathrm{F}_{1^{-}} \mathrm{F}_{2}-\mathrm{F}_{3}$, hybrid combinations were studied. In field experiments, important physiological parameters of plant water metabolism were determined by the method of total water content in the leaves:

The dominance coefficient in G'1 hybrids is given in G.M.Veil and R.E.Atkins work, calculated according to the formula S.Wright [5].

$$
h p=\frac{F_{1}-M R}{R-M R}
$$

hp - dominance coefficient;

$\mathrm{F}_{1}$ - the arithmetic mean of the hybrid sign;

MR - the arithmetic mean of both parental form symbols; form sign

$\mathrm{R}$ - the arithmetic mean of the best parent

The results obtained from the experiments show that B.A. Dospekhov [4] carried out statistical processing. In this case, the indicators obtained for each character were analyzed by variance, ie the reliability of differences between varieties and hybrids was determined by the Fisher criterion $\left(F_{1}\right)$, the total error of the experiment $\mathrm{Sx}$, the error of mean differences $\mathrm{Sd}$ and the smallest difference (EKF) $95 \%$.

Water scarcity of sunflower varieties, ridges or hybrids, i.e. the degree of susceptibility to a model drought on a given character, the coefficient of resilience (Kmos.) Is as follows S. A. Ebarhart is evaluated by definition according to the W.A. Russell formula:

$$
\mathrm{Kmos} \%=\frac{\left(X_{1} \cdot 100\right)}{X_{2}}-100 \%
$$

here the $\mathrm{x} 1$ is the water shortage indicator of the sign, the $X_{2}$ is the water supply indicator of the sign. During the ripening of sunflowers baskets were selected and individual selections for each hybrid combination

\section{RESEARCH RESULTS AND THEIR ANALYSIS}

In our experiments, the total amount of water in the leaves of sunflower varieties and their hybrids in the conditions of optimal water supply (optimal background) in the flowering-harvesting phase was $70-72 \%$ of soil moisture compared to ultimate field moisture capacity (UFMC), and $48-50 \%$ in the background of modeled drought. the total amount of water in the leaves of sunflower plants was studied simultaneously in the plants. In the group of sunflower varieties identified under optimal water conditions, the highest total amount of water in the leaves was recorded in the foreign Jant lower variety (79.1\%). This variety and Luchaferul and S-NS-N$2011 \mathrm{~g}$ varieties did not differ significantly from each other in terms of character, and the lowest water content in the leaves was detected in Tels $(76.3 \%)$ cultivars, and this variety differed reliably from all other varieties in Table 1. 
SJIF Impact Factor 2021: 8.013| ISI I.F.Value:1.241| Journal DOI: 10.36713/epra2016 $\quad$ ISSN: 2455-7838(Online)

EPRA International Journal of Research and Development (IJRD)

Volume: 6 | Issue: 12 | December 2021

- Peer Reviewed Journal

Table 1

Total water content, dominance (hr) and flexibility (Kmos.) Coefficients in the leaves of sunflower varieties and $F_{1}-F_{2}-F_{3}$ plants

\begin{tabular}{|c|c|c|c|c|c|c|c|c|c|c|c|c|}
\hline \multirow[b]{2}{*}{$\begin{array}{l}\mathbf{T} / \\
\mathbf{p}\end{array}$} & \multirow[b]{2}{*}{$\begin{array}{l}\text { Varieties and hybrid } \\
\text { combinations }\end{array}$} & \multicolumn{5}{|c|}{ First generation $\mathbf{F}_{1}$} & \multicolumn{3}{|c|}{ Second generation $\mathbf{F}_{2}$} & \multicolumn{3}{|c|}{ Third generation $\mathbf{F}_{3}$} \\
\hline & & $\begin{array}{c}\text { Optimal } \\
\text { background } \\
(\%) \text { (soil } \\
\text { humidity } \\
\text { UFMC } \\
\text { relatively 70- } \\
72 \%)\end{array}$ & hp & $\begin{array}{c}\text { Modeled } \\
\text { background } \\
\text { (\%) (Soil } \\
\text { humidity } \\
\text { UFMC } \\
\text { relatively 48- } \\
50 \%)\end{array}$ & hp & $\underset{\%}{\operatorname{Kmos}}$ & $\begin{array}{c}\text { Optimal } \\
\text { background } \\
(\%) \text { (soil } \\
\text { humidity } \\
\text { UFMC } \\
\text { relatively } \\
\mathbf{7 0 - 7 2 \% )}\end{array}$ & $\begin{array}{c}\text { Modeled } \\
\text { background } \\
\text { (\%) (Soil } \\
\text { humidity } \\
\text { UFMC } \\
\text { relatively } \\
\text { 48-50\%) }\end{array}$ & $\begin{array}{c}\text { Kmo } \\
\text { S, } \\
\%\end{array}$ & $\begin{array}{c}\text { Optimal } \\
\text { background } \\
(\%) \\
\text { (soil } \\
\text { humidity } \\
\text { UFMC } \\
\text { relatively } \\
(\mathbf{7 0 - 7 2 \% )} \\
\end{array}$ & $\begin{array}{c}\text { Modeled } \\
\text { backgroun } \\
\text { d (\%) (Soil } \\
\text { humidity } \\
\text { UFMC } \\
\text { relatively } \\
\text { 48-50\%) }\end{array}$ & $\underset{\%}{\mathrm{Kmos},}$ \\
\hline 1. & KK-1 & $72,4 \pm 0,3$ & - & $70,5 \pm 0,3$ & - & $-2,62$ & $73,0 \pm 0,3$ & $72,3 \pm 0,4$ & $-0,95$ & $75,2 \pm 0,1$ & $73,4 \pm-0,1$ & $-2,39$ \\
\hline 2. & KK-60 & $74,4 \pm 0,3$ & - & $73,2 \pm 0,2$ & - & $-1,61$ & $74,6 \pm 0,7$ & $73,9 \pm 0,2$ & $-0,93$ & $74,3 \pm 0,2$ & $73,9 \pm 0,2$ & $-0,54$ \\
\hline 3. & Luchaferul & $78,2 \pm 0,2$ & - & $75,6 \pm 0,3$ & - & $-3,32$ & $78,5 \pm 0,5$ & $75,3 \pm 0,3$ & $-4,07$ & $77,5 \pm 0,3$ & $75,9 \pm 0,5$ & $-2,06$ \\
\hline 4. & Tels & $69,8 \pm 0,3$ & - & $68,6 \pm 0,4$ & - & $-1,72$ & $70,4 \pm 0,3$ & $68,8 \pm 0,3$ & $-2,27$ & $73,6 \pm 0,3$ & $72,9 \pm 3,0$ & $-0,95$ \\
\hline 5. & S-Alstor & $73,6 \pm 0,3$ & - & $72,2 \pm 0,4$ & - & $-1,90$ & $72,3 \pm 0,2$ & $71,8 \pm 0,5$ & $-0,69$ & $75,5 \pm 0,3$ & $72,3 \pm 0,3$ & $-4,49$ \\
\hline 6. & Jant lower & $79,1 \pm 0,3$ & - & $75,2 \pm 2,1$ & - & $-5,17$ & $75,6 \pm 0,04$ & $72,3 \pm 0,1$ & $-4,36$ & $78,8 \pm 0,3$ & $75,3 \pm 0,1$ & $-4,44$ \\
\hline 7. & C-HS-H-2011г & $78,8 \pm 0,4$ & - & $73,3 \pm 0,5$ & - & $-6,34$ & $81,2 \pm 0,2$ & $76,9 \pm 0,4$ & $-5,29$ & $78,4 \pm 0,3$ & $77,0 \pm 0,3$ & $-1,78$ \\
\hline 8. & Luchaferul x KK-1 & $76,6 \pm 0,3$ & 1,8 & $72,9 \pm 0,4$ & 0,6 & $-4,83$ & $77,4 \pm 0,4$ & $75,6 \pm 0,3$ & $-2,32$ & $77,2 \pm 0,3$ & $75,3 \pm 0,1$ & $-2,46$ \\
\hline 9. & Tels x KK-1 & $75,7 \pm 0,1$ & $-0,1$ & $74,6 \pm 0,7$ & 0,1 & $-1,45$ & $77,1 \pm 0,3$ & $74,6 \pm 0,7$ & $-3,24$ & $76,8 \pm 0,2$ & $75,2 \pm 5,8$ & $-2,08$ \\
\hline 10. & S-Alstor x KK-1 & $79,0 \pm 0,2$ & 0,3 & $75,2 \pm 0,5$ & 0,9 & $-4,81$ & $79,0 \pm 0,1$ & $75,7 \pm 0,6$ & $-4,18$ & $77,5 \pm 0,3$ & $76,6 \pm 0,3$ & $-1,16$ \\
\hline 11. & C-HS-H-2011г х KK-1 & $76,4 \pm 0,3$ & 1,2 & $74,9 \pm 0,7$ & 1,4 & $-1,96$ & $80,0 \pm 0,1$ & $76,6 \pm 0,5$ & $-4,25$ & $75,7 \pm 0,2$ & $73,9 \pm 0,5$ & $-2,37$ \\
\hline 12. & Jant lower x KK-1 & $76,8 \pm 0,4$ & $-3,0$ & $73,4 \pm 0,3$ & $-2,6$ & $-4,42$ & $78,0 \pm 0,3$ & $76,5 \pm 0,1$ & $-1,92$ & $77,4 \pm 1,6$ & $75,7 \pm 0,3$ & $-2,19$ \\
\hline 13 & Сор Голлипс х КК-1 & $75,4 \pm 0,3$ & -0.9 & $73,2 \pm 0,2$ & -1.0 & $-1,88$ & $76,6 \pm 0,4$ & $73,6 \pm 0,2$ & $-3,91$ & $74,3 \pm 0,2$ & $72,3 \pm 0,2$ & $-2,69$ \\
\hline 14. & Ак-12/95 x КК-1 & $74,6 \pm 0,3$ & 0,6 & $72,2 \pm 0,4$ & 0.04 & $-3,21$ & $72,3 \pm 0,2$ & $71,0 \pm 0,5$ & $-1,79$ & $75,5 \pm 0,3$ & $73,3 \pm 0,3$ & $-2,91$ \\
\hline 15. & $\begin{array}{l}F_{1}(\text { Jant lower } \times \text { KK-1 }) \times \\
\left(F_{1}(\text { AK-12/95 x KK-1) }\right.\end{array}$ & $78,9 \pm 0,2$ & 1.9 & $77,4 \pm 0,2$ & 2,6 & $-1,90$ & $77,2 \pm-7,0$ & $76,1 \pm 0,3$ & $-1,42$ & $76,7 \pm 0,3$ & $75,3 \pm 0,1$ & $-1,82$ \\
\hline 16. & $\begin{array}{c}\mathrm{F}_{1}(\mathrm{C}-\mathrm{HS}-\mathrm{H}-2011 г . \mathrm{x} \mathrm{KK}-1) \\
\mathrm{x} \mathrm{F}_{1}(\mathrm{~S}-\mathrm{Alstor} \times \mathrm{KK}-1)\end{array}$ & $79,9 \pm 0,4$ & 1,3 & $76,9 \pm 0,5$ & $-1,0$ & $-3,75$ & $77,7 \pm 11,0$ & $77,1 \pm 0,1$ & $-0,77$ & $78,0 \pm 0,1$ & $76,9 \pm 0,4$ & $-1,41$ \\
\hline 17. & $\begin{array}{c}F_{1}(\text { Сор Голлипс x КК-1) x } \\
\left(\mathrm{F}_{1}(\text { Tels x KК-1) }\right.\end{array}$ & $77,6 \pm 0,5$ & 0,4 & $76,5 \pm 0,3$ & 1,8 & $-1,42$ & $78,0 \pm 1,5$ & $76,4 \pm 0,2$ & $-2,05$ & $80,0 \pm 0,1$ & $78,9 \pm 0,3$ & $-1,37$ \\
\hline
\end{tabular}

2021 EPRA IJRD | Journal DOI: https://doi.org/10.36713/epra2016 | www.eprajournals.com |91 | 


\section{SJIF Impact Factor 2021: 8.013| ISI I.F.Value:1.241| Journal DOI: 10.36713/epra2016 ISSN: 2455-7838(Online) \\ EPRA International Journal of Research and Development (IJRD) \\ Volume: 6 | Issue: 12 | December 2021 \\ - Peer Reviewed Journal}

In normal $F_{1}$ hybrids of varieties, the highest performance on this trait was in the combination of SAlstor x KK-1 (79.0\%), Luchaferul x KK-1 (76.6\%) and Jant lower $\mathrm{x} \mathrm{KK}-1$ (46.8\%), with a relatively low performance. and S-NS-H-2011g x KK-1 and Tels $\mathrm{x}$ KK-1 hybrid combinations $(76.4 \%$ and $75.7 \%$, respectively). In the combination of $\mathrm{F}_{1}$ (S-Alstor $\mathrm{x}$ KK1) of the Jant lower and Tels varieties, which have the highest and lowest values of the total amount of water in the leaves, the marking index was $79.0 \%$, and the dominance process (hp) was 0.3 . showed an incomplete predominance of the high-yielding variety in the hybrid character trait. $F_{1}$ (Jant lower x KK-1) of KK-60, KK-1 and S-Alstor sunflower varieties (total water content in leaves $72.4 \%, 73.6 \%$ and $72.4 \%$, respectively) with close relative to each other in the hybrid combination was $76.8 \%$, and the predominance was $\mathrm{hr}=-3.0$, i.e., in this combination, the sign of total water content in the leaves was inherited in a state of negative heterosis.

Inheritance of characters in the case of positive heterosis with predominance was found to be in combinations of $\mathrm{F}_{1}$ (Luchaferul $\left.\mathrm{x} \mathrm{KK}-1\right)$ and $\mathrm{F}_{1}$ (SNS-H-2011g x KK-1) (hp 1,8 and 1,2, respectively). In the second generation, these $F_{2}$ (Luchaferul $x$ KK-1) and $\mathrm{F}_{3}$ (S-NS-H-2011g x KK-1) hybrid combinations accounted for $77.4 \%$ and $80.0 \%$, while in the third generation, $75.3 \%$ and 73 , respectively, was equal to $9 \%$.

In the first generation of complex hybrids, the highest values for the total amount of water in the leaves are $\mathrm{F}_{1}$ (Jant lower $\left.\mathrm{x} \mathrm{KK}-1\right) \mathrm{x}\left(\mathrm{F}_{1}\right.$ (Ak-12/95 x KK-1) and $F_{1}$ (S-NS-H-2011g. X KK-1 ) x $F_{1}$ (S-Alstor $\mathrm{X} \mathrm{KK}-1)(79.9 \%$ in each, $78.9 \%$ in each). -1$)$ in the hybrid combination $(77.6 \%$, respectively). In the combination of these complex hybrids $\mathrm{F}_{1}$ (Jant lower $\mathrm{x}$ $\mathrm{KK}-1) \times\left(\mathrm{F}_{1}(\mathrm{Ak}-12 / 95 \times \mathrm{KK}-1)\right.$, the total water content in the leaves was $79.9 \%$ and the dominance coefficient (hp) was 1.9., the inheritance of the character took place in a state of extreme dominance, as in the parental forms- simple $F_{1}$ hybrids. Another combination of complex hybrids in $\mathrm{F}_{1}$ (Sor Gollips $\mathrm{x}$ $\mathrm{KK}-1) \times\left(\mathrm{F}_{1}\right.$ (Tels $\left.\mathrm{x} K \mathrm{KK}-1\right)$ had a dominance coefficient of 0.4 , ie in this hybrid the inheritance of a trait is recorded in its hybrids of its parental forms $F_{1}$. passed in the state of incomplete dominance $(\mathrm{hp}=0.4)$ of the high-performance hybrid, but not in the state of extreme dominance given. Complex hybrids ranged from the lowest in the $\mathrm{F}_{2}$ generation to $77.2 \%-78.0 \%$, respectively, and in the $\mathrm{F}_{3}$ generation from the highest and lowest in total leaves $(76.7 \%-80.0 \%)$. was recorded.

In all the genotypes studied in the modeled drought conditions, it was found that the total amount of water in the leaves of sunflower plants decreased to a different extent compared to the conditions of optimal water supply. In the case of water scarcity, Luchaferul $(75.6 \%)$ and Jant lower $(75.2 \%)$ varieties had the highest total water content in the leaves, while the Tels variety $(68.6 \%)$ had the lowest water content. In ordinary $F_{1}$ hybrids of varieties, the highest indicator of total water content in the leaves was in the combination of S-Alstor x KK-1, S-NS-H-2011g x KK-1 and Tels x KK-1 (75.2\%, 74.9, respectively). \% and 74.6\%), while the lowest was found in the combination of Luchaferul $x$ KK-1 (72.9\%). In the combination of $F_{1}$ Luchaferul $x$ KK-1 of Luchaferul and KK-1 varieties $(75.6 \%$ and $70.5 \%$, respectively), which differ reliably from each other in terms of total water content in the leaves of the plant, the sign index is $75.6 \%$, while the dominance coefficient hr was 0.6 , and the inheritance was intermediate. Other hybrid components close to each other in terms of sign performance in hybrids of Jant lower and KK-1 varieties $(75.2 \%$ and $70.5 \%$, respectively), ie in combination with $\mathrm{F}_{1}$ (Jant lower $\mathrm{x}$ $\mathrm{KK}-1$ ), the sign index is $73.4 \%$ hp while -2.6 , i.e., in this case the inherited plants were completely dominated by the KK-1 variety, which had less water content in the leaves.In complex $F_{1}$ hybrids in conditions of water scarcity in the soil, the highest values of the total water content of the leaves in the combinations $\mathrm{F}_{1}$ (Jant lower $\mathrm{x}$ KK-1) x $\left(\mathrm{F}_{1}(\mathrm{Ak}-12 / 95 \mathrm{x}\right.$ $\mathrm{KK}-1)$ are $77.4 \%$, respectively, and the lowest values are $77.4 \% . \mathrm{F}_{1}$ (S-NS-H-2011g. X KK-1) x $\mathrm{F}_{1}$ (S-Alstor $\mathrm{x}$ KK-1) and $\mathrm{F}_{1}$ (Sor Gollips $\mathrm{x}$ KK-1) x $\mathrm{F}_{1}$ (Tels x KK1) in combinations (76 respectively), $9 \%$ and $76.5 \%$, respectively. Combinations of simple $F_{1}$ hybrids inherited in a state of over-predominance of the total water content mark on plant leaves are complex $\mathrm{F}_{1}$ (In the hybrid of rim lower $x \mathrm{KK}-1) \times \mathrm{F}_{1}(\mathrm{Ak}-12 / 95 \times \mathrm{KK}$ 1 ), the sign index was $77.4 \%$, and the dominance coefficient hp was 2.6. The rim showed that the lower $\mathrm{x}$ KK-1 simple hybrid did not prevail. While the simple hybrids $\mathrm{F}_{1}$ are $\mathrm{hr}=-1.0$ in Sor Gollips $\mathrm{x} \mathrm{KK}-1$ and $\mathrm{hp}=$ 0.1 in Tels $x$ KK-1, the complex $F_{1}$ (Sor Gollips $x$ KK1) $x F_{1}$ (Tels) of these two hybrids $x K K-1$ ) in the combination was $h p=1.8$, ie the trait under study was inherited in a state of positive predominance, in contrast to the parent forms - ordinary $F_{1}$ hybrids. In the $\mathrm{F}_{1}$ generation of ordinary hybrids to the lowest index (71.0\% $-76.6 \%$, respectively) and in the $\mathrm{F}_{3}$ generation to the highest and lowest values of total water content in the leaves $(72.3 \%-76.6 \%)$ was found to be in the range.

\section{CONCLUSION}

In general, the total amount of water in the leaves of plants in conditions of water scarcity in the soil relative to the water regime decreased by $1.6-6.3 \%$ in varieties, $1.4-4.8 \%$ in simple hybrids $F_{1}$ and 1.4$3.7 \%$ in complex hybrids $F_{1}$. In the second-generation cultivars studied, it decreased by $0.9-5.3 \%$, in simple $\mathrm{F}_{1}$ hybrids by $1.8-4.2 \%$, and in complex $\mathrm{F}_{2}$ hybrids by $0.8-2.0 \%$. In the third-generation cultivars studied, it decreased by $0.9-4.5 \%$, in simple $\mathrm{F}_{3}$ hybrids by 1.2 $2.5 \%$, and in complex $\mathrm{F}_{2}$ hybrids by $1.4-1.8 \%$. This indicates that the total amount of water in the leaves of 
EPRA International Journal of Research and Development (IJRD)

Volume: 6 | Issue: 12 | December 2021

- Peer Reviewed Journal

plants depends not only on the conditions of water supply, but also on the genotypic composition. The results showed that this trait is inherited differently in simple and complex $\mathrm{F}_{1}, \mathrm{~F}_{2}$ and $\mathrm{F}_{3}$ hybrids under different water regime conditions, with $\mathrm{F}_{1}$ hybrid combinations changing depending on the dominance coefficients and water supply conditions in hp as well as the composition of the parent forms of hybrids.

\section{LIST OF USED LITERATURE}

1. Abdukarimov D.T., Ostanakulov T.E., Lukov M.K. Breeding and Seed Workshop. // Zarafshan Publishing House. Samarkand, 1993. 150 p.

2. Amanova M., Rustamov A. Capital varieties of sunflower. // Journal of Agriculture of Uzbekistan. № 5. 2004. 24 p.

3. Alikulov R. Yu., Xaldarov Sh.M., Samiev X.S. Utochnenie formula vodopotrebleniya xlopchatnika. I/Tez.dokl. I-syezda fiziologov rast. Uzbekistan. - Tashkent, 1991. -S. 98.

4. Dospexov B.A. Methodology of field opyta. M.: "Agropromizdat", 1985. p. 251.

5. Abdul Djalil Hassan Muhammad Al Harani. Effektivnost parnoy $i$ slozhnoy gibridizatsii $v$ uluchshenii selektsionno - tsennyx priznakov xlopchatnika: Avtoref. dis. kand. s / x. nauk. Tashkent, 1995. - $19 \mathrm{p}$. 